\title{
Digital Self-Evaluation and the Cybernetic Regime: A Sketch for a Materialist Apparatus Analysis
}

\author{
Simon Schaupp \\ Technical University of Munich, Germany, s.schaupp@tum.de \\ https://www.mcts.tum.de/en/personen/researchers/simon-schaupp/
}

\begin{abstract}
Building on an exemplary analysis of self-tracking applications, this paper develops a materialist approach to the methodology of apparatus analysis. It builds on the Foucauldian concept of the apparatus, which it then subdivides into a micro apparatus, as a concrete digital technology, and a macro apparatus, as the superordinate regime to which the micro apparatus contributes. To bridge these two concepts, the term "urgent need" is used to ask to which broader social problems a given apparatus reacts. Contrary to the approaches of "new materialism", this paper insists on an analytical divide between discourse and matter on the one hand and action structure on the other hand, in order to consider politico-economic power relations. Using this methodology, the relationship between the techno-practice of self-tracking and a broader cybernetic regime is illustrated.
\end{abstract}

Keywords: Apparatus, Self-Tracking, Cybernetics, Materialism, Critical Realism

Acknowledgements: I am grateful to Sabine Maasen, Uli Meyer and two anonymous reviewers for constructive feedback and to Verena Zink for assisting me in editing this paper.

\section{Introduction}

Technologies of digital self-evaluation in their distinctive forms, from self-tracking to social media, are enjoying steady popularity. Self-portrayal on different platforms, in combination with the continuous feedback of particular communities, allows for a new form of reflective self-adaptation and reassurance. In particular, the practice of selftracking, i.e. intentional self-quantification by means of digital technologies, is a prime example of digital self-evaluation. However, there are two aspects of the term selfevaluation which go beyond self-tracking. First, the term is open to different kinds of technologies, of which self-tracking applications are only one particularly characteristic example. Second, it already entails an interpretation: the relevant technologies are not only about tracking, but are also always about valuation, which assumes a fundamental will to self-optimise on the part of the users. However, the paradigm of evaluation has not only developed with the digital technologies researched in this publication. Michael Power (1997) spoke of an "audit society" in the context of completely different technologies in the 1990s, a diagnosis on which I will elaborate further.

For the critical social science research of digital self-evaluation, one question is raised first and foremost: why do people self-evaluate? Why do they track and measure their steps, their meals, their sex lives, and publish self-portraits, which are then discussed and reviewed? In mass media reports about selfies, self-tracking, and so on, this question is mostly answered pejoratively as a proliferating narcissistic obsession (cf. Weintraub 2013). The disconcert manifesting in this answer is understandable to 
an extent, but does not contribute to the understanding of self-evaluation practices. Instead, in social sciences literature the aspect of self-optimisation is moved to the foreground. This analysis is certainly accurate but it explains the how of self-evaluation rather than the why. It is therefore time for an evaluation of the evaluation of self-evaluation.

The basic hypothesis of this paper is that the lack of explanatory power of many evaluations of self-evaluation in the social sciences goes back to conceptual and methodological origins. Research that only focuses on the interaction of users with certain media technologies inevitably loses sight of the politico-economic context through its conceptual individualism. However, as this context can lead to important explanatory approaches, I plead for an approach that focuses on overarching power structures apart from the interaction between users and technologies.

For such an approach, Michel Foucault's term of the apparatus offers a good starting point for a critical analysis of digital technologies for two reasons. First, it takes seriously the discursive as well as the material aspects of digital technologies. Second, it enables a conceptual coupling of both a micro and a macro analysis of the power structures in which the object of research is embedded. Following critical-realist discourse analysis (Fairclough, Jessop and Sayer 2004; Fairclough 2005; Flatschart 2015), a materialist apparatus analysis is outlined as a methodological proposition for the critical analysis of digital self-evaluation. This approach is a materialist one in two senses. On the one hand, it assumes an analytical divide between the discursive and the material. According to this approach, when analysing the use of digital technologies, materiality has to be acknowledged as an independent category with regards to its social effects. On the other hand, it assumes that for a critical analysis of modern media constellations, the politico-economic context must not be disregarded.

According to Gilles Deleuze (1997, 184), two different research strategies can be carved out of Foucault's writings concerning apparatus. The first and more broadly received variant can be described as a macro apparatus. It understands the apparatus as an abstract regime inherent to the social field as a whole, such as the apparatuses of confinement or confession. The second variant, an approach appearing especially in the context of Foucault's "microphysics of power", is described as "diffuse and heterogenous multiplicity, 'micro-dispositifs'." (Ibid.). This concept of micro-dispositifs or micro apparatuses can help to grasp concrete entanglements of discourse and materiality, such as specific technologies. As stated above, for a materialist apparatus analysis both levels are relevant and should be taken into account.

Based on this concept, I will sketch a materialist apparatus analysis in three steps using the example of self-tracking. In the first step, self-tracking will be described as an example of the micro apparatus of digital self-evaluation in its material and discursive functionality. In the second step, I will interpret this micro apparatus with recourse to the term social "urgent need" (Foucault 1980, 195). This term links micro and macro apparatuses as it asks to which social problems a given micro apparatus reacts. Selftracking can therefore be interpreted as a reaction to an "urgent need" for control in a post-Fordist economy. In the third step, I will suggest the term "cybernetic regime" to indicate a possible superordinate macro apparatus. Finally, I will evaluate my evaluation (of the evaluation) of self-evaluation and wonder if it is ever possible to exit the feedback loop. 


\section{The Digital Micro Apparatus: Self-Tracking}

In the following section, I will operationalise the term micro apparatus for an analysis of concrete digital technologies. Eugster (2013) and Lepa et al. (2014) undertook useful operationalisations of the term (micro) apparatus for the sociology of media and technology. However, to be applied to the analysis of digital technologies, this term needs further elaboration and refinement. Technologies of digital self-evaluation are concrete material-discursive artefacts within a specific historical and technological context. Thus, their examination demands an adjustment of apparatus analysis. Specifically, the relationship between the material and the discursive elements of the apparatus needs to be clarified based on an - inevitably rough - metatheoretical excursion.

Foucault $(1980,119)$ describes the term apparatus as "a thoroughly heterogeneous ensemble consisting of discourses, institutions, architectural forms, regulatory decisions, laws, administrative measures [...] - in short, the said as much as the unsaid." Thus, different formations are taken into consideration that are not sufficiently described by the term discourse. ${ }^{1}$ Some of Foucault's statements can be interpreted in a way that suggests that he denies the mere existence or ascertainability of anything external to discourse, which is why these statements have been criticised as "antirealism" or "superidealism" (Flatschart 2015, 12). However, the term apparatus can also be read as an attempt to consider the interplay between the discursive and the nondiscursive. Institutions, architecture, laws, etc. emerge as part of discursive social practices, but are not reducible to discourse. What the discursive as well as the non-discursive elements of the apparatus have in common is their capacity to structure actions. On the one hand, the apparatus consists of discursive practices, but on the other hand, it entails the essential function to produce, arrange and structure them (Agamben 2009,8 ). It is therefore a 'socio-material' infrastructure.

In their elaborations on socio-materiality, theorists of "new materialism" or actor network theory make the valid and important point that the social is always also material (e.g. Latour 1988). From that, however, they draw the wrong conclusion in claiming that the material aspects of the world are only accessible through discourse and are therefore produced by the symmetric "intra-action" of elements which have no distinct prior existence (Barad 2007). This poses two central problems. First, generally denying a differentiation of separate entities (not only between discourse and materiality but between categories in general) prevents us from identifying different degrees of causality (Sayer 2000, $34 \mathrm{ff}$ ). Second, it is reducing ontology to epistemology and thereby veiling the specifically material elements of the social which "new materialism" wanted to emphasise in the first place. Thus, I argue for a critical-realistic ontology that retains an analytic divide between discourse and materiality (later between action and structure) without renouncing their empirical entanglement in the micro apparatus (Leonardi 2013). Flatschart $(2015,36 \mathrm{f})$ notes that: "This does not mean that discourse is not material or that it is material in the sense of the 'solid materiality' of, for example, natural objects espoused by vulgar materialist approaches. Materiality is a way of expressing the historically specific character of the relatively determinate causal efficacy of real (social) objects, and as such it certainly includes discursive objects." Thus, the digital

\footnotetext{
${ }^{1}$ With the term discourse, I point to a critical-realistic reformulation of Foucault with Maarten Hajer: "a specific ensemble of ideas, concepts, and categorizations that are produced, reproduced and transformed to give meaning to physical and social relations" (Hajer, quoted in Flatschart 2015, 11).
} 
micro apparatus always entails material as well as discursive elements whose relationship should be thought of as a dialectic one, an interplay in which distinct elements are mutually generative.

The analysis of a technological micro apparatus has to start with two superordinate descriptions: $(A)$ the description of the technology in its functionality and (B) the description of its discursive context. As I will focus on conceptual issues here, methods of data collection and analysis will not be addressed. Neither will I describe the researched self-tracking technologies in detail. However, there is an extensive literature on methods for the ethnographic description of technologies (e.g. Vannini 2009, Fielding et al. 2008), of which those working with the concept of affordances in particular seem to favour a materialist apparatus analysis (e.g. Volkoff and Strong 2013). Regarding methodologies of discourse analysis, interested readers can turn to the work of Norman Fairclough $(2005 ; 2013)$. The data summarised here is presented elsewhere in detail (Schaupp 2016a).

I have analysed self-tracking technologies in various areas of application such as exercise, health/diet, time management, discipline, personal rating and overall data correlation. In addition, I analysed the applications concerning their functionality, as well as (audio-) visual and text-based advertisements. This approach offers the advantage that it grasps the specific interpellation that the corresponding technologies direct to their users. It can be assumed that these interpellations do not vanish without any effect. The exact extent to which they have an actual impact is not traceable by the collected data and would require semi-structured interviews with self-trackers in addition to the data from advertisements. However, this research is not about revealing the intentions of the respective actors, but about tracing the relationship between the technological artefacts and the political-economic macro-structures. Therefore, I suggest a phenomenological approach for the first step, which could be the following:

A) The description of the technology's functionality should, especially if it is a digital technology such as the ones used for self-tracking, be subdivided into descriptions of the front-end visible to the users and the invisible back-end, where the machine processes run. Goffey $(2008,16)$ points out how it is essential for understanding software to also understand its base, the underlying algorithms. These algorithms automatically use certain rules for concrete problems. In that way, they sort the functions of the computers and thus the interactions executed on them as well. That is why the algorithm, in Foucauldian terminology, should not be seen as a technological discourse or as a statement as Goffey suggests (2008, $17 \mathrm{f}$ ), but as a digital micro apparatus. As such, its technological functionality must be described.

Digital self-evaluation is about transforming the description of human activities to machine-readable information, as well as presenting them to the users. A central question is, therefore, which reductions are undertaken? According to which rules are qualitative data transformed into scaled, quantitative data? How are certain entries reduced to prescribed categories? Another important question is: which worldviews and assumptions concerning the users are inscribed into the program, and what cultural norms and concepts does it refer to?

The basic function of self-tracking technologies is the feedback of processed data about the self to the user. Contrary to other self-measurement technologies, such as the body scale, self-tracking in most cases does not measure the body itself, but its activities. A special feature of digital feedback in self-tracking - contrary to personal feedback - can be found in its immediacy. When, for example, a digital worker uses part of her paid worktime to simply stare at the screen, it can take months until this is noticed by her supervisors or herself. When she shortens her running route, she might 
never know how this plays out on her caloric intake. With the use of self-tracking technology these feedback loops are shortened. Deviation ${ }^{2}$ and feedback thus ideally happen at the same time. For the disciplining effects of this sort of feedback, the connection of sensory machines with human feedback providers is central. A flashing display by itself could not replace the mechanisms of social reputation under current conditions. Therefore, nearly all self-tracking technologies provide the option of sharing one's data with a virtual peer group. Along with this feedback loop goes the possibility of data correction by the user. This also explains the high degree of reliability of selftracking data. Thus, a system of mutual feedback between users, machines and observers is established.

B) The second superordinate description that has to be given in order to analyse the technological micro apparatus concerns the discursive context in which the apparatus is set out. However, the term context is not to be understood as something separate from the apparatus itself. With Foucault, by contrast, I understand the apparatus to be a "system of relations" between the discursive and the non-discursive elements (Foucault 1980, 194). Generally, the methodology of apparatus analysis allows for the collection and analysis of all kinds of discursive data, from documents to qualitative interviews. In fact, it might be important to overcome the focus of discourse analysis on mere text-based statements. In addition to textual elements, audio-visual material is also relevant for the analysis of digital micro apparatuses. Just as with the analysis of text fragments, this is about extrapolating statements. In addition, it is important to consider menu navigation of the software or link structures on websites at the interface of material functionality and discursive context.

The data from advertisements for self-tracking technologies analysed here indicates that the measured activities are mostly framed in terms of performance. On the visual level, the image of the mountaineer reaching a summit is used strikingly often (not only in sports tracking technologies). This can be interpreted as a "viseo-typical key image" (Ludes 2001) to display the connection between performance and success. It is important to note that the quantification of performance in self-tracking expands beyond its classic domains of sports and wage labour. Even in advertisements for health-tracking, it is regularly emphasised that the measured data is "relevant to performance" (Biotrakr 2015). Around the concept of performance, clusters of economic terminology can be found conspicuously often. "Management" becomes an overall term that can be used for everything including health. Trust and reputation turn into "capital". The quantifying and presenting processes of self-tracking are thereby portrayed as the basis for a rational management of the self. In this respect, they can be understood as a sort of bookkeeping in the company of the self (Schaupp 2016b).

When, for example, the advertisement for the running app Runtastic states that its aim is to "improve performance constantly" (Runtastic b [n.d.]), it quickly becomes apparent that "self-knowledge through numbers", as the slogan of the quantified-self movement states (Quantified Self, n.d.), is by no means an end in itself. If one follows the advertisement discourses, tracking should lead to an optimised self instead. This optimisation of the self is often framed as an increase in performance, but self-realisation also plays a central role. As is emphasised over and over again: this is not about making users adhere to general standards. Runtastic for example emphasises that it is all about "individual goals, no matter how defined" (Runtastic a [n.d.]). On the visual level it is striking that advertisements mainly display focused individuals. Groups are

${ }^{2}$ This usually does not refer to the deviation from a general standard, but to the deviation from an optimisation course. 
mostly displayed abstractly or in the background. Through this emphasis on the individual, self-tracking succeeds at enforcing neo-Tayloristic methods of rationalisation for all areas of living, without attacking post-Fordist individualism. In both variants of self-optimisation, a strong instrumental conception of the self is expressed by techniques to manipulate one's weaker self. The three most important mechanisms of selfmanipulation are the comparison to other users in rankings, different variants of gamification (Whitson 2013), as well as monetary incentives working through contracts with oneself (Schaupp 2016a, $58 \mathrm{ff}$ ). With Beeminder this instrumental self-relation is expressed in the clear imperative: "Engineer yourself!" (Beeminder 2015).

\section{The Urgent Need: Controlled Flexibility}

According to Foucault $(1980,195)$, a "major function" of the apparatus is to respond to an "urgent need" at any given historical moment. The apparatus thus always presents an attempt to find a solution for an existing social problem insofar as the apparatus, according to Foucault, always entails a strategic function (lbid.). This strategy is not to be understood as intentional: it has "nothing to do with any kind of strategic ruse on the part of some meta- or trans-historic subject conceiving and willing it." (Ibid.). It is a strategy without a strategist. The apparatus cannot eliminate the "urgent need", which it was made to overcome, in the sense of a mechanical repair. Instead, the apparatus, through its overdetermining way of functioning, opens up new "urgent needs" for every old one it overcomes. The apparatus reacts to an "urgent need" and seeks to overcome it. As a result, it creates effects which counteract this attempt and create additional "urgent needs". For a materialist apparatus analysis, the "urgent need" serves as the hinge between micro and macro apparatus. By identifying the superordinate "urgent needs" to which an apparatus reacts, we come closer to an explanation of its social function.

The identification of an "urgent need" needs to proceed empirically as well as theoretically. It is easy, in most cases, to empirically identify concrete problems that a given technology is supposed to fix. This can be done by semi-structured interviews with developers, but also by analysing advertisements, as I did in the study summarized here. However, a materialist apparatus analysis must emphasise the politico-economic context of the "urgent need". Therefore, identifying the urgent need cannot be done by empirical research alone, but requires a theoretical framework. To illustrate this, I will elaborate in the following section how self-tracking can be understood as a reaction to an "urgent need" for control in post-Fordism. This is not to argue, however, that the examined micro apparatus is the only social reaction to the respective "urgent need" or vice versa. Instead, it must be understood as part of a complex network of relations. ${ }^{3}$ In the following paragraphs, I will demonstrate the methodological function of the "urgent need" concept by first giving short examples of how an urgent need can be identified a) empirically and b) theoretically, and then sketching out how self-tracking reacts to this "urgent need".

Self-tracking still partially consists of classic workplace surveillance. Thus, many applications offer so-called 'team versions' of their programs which can be used by companies to control their employees. RescueTime for example offers a time management tool that can be installed on computers to track every keystroke and make regular

${ }^{3}$ Obviously, the relation of self-tracking practices to societal power structures is not limited to the economic level. Particularly relevant are connections to gender relations or to societal body norms about which the self-tracking discourse adds informative findings (Lupton 2015b; Schaupp 2016b). 
screenshots of the employees' displays. The company consequently describes its program as a "business intelligence tool" (RescueTime a [n.d.]). This points to a persistent "urgent need" for control, which is inherent to capitalist wage labour itself because it deals with the problem of the transformation of bought labour-power into real labour. However, self-tracking technologies are suitable, above all, to control independent, creative, or self-employed work. Thus, another RescueTime slogan runs: "As an entrepreneur you need to work efficiently. RescueTime monitors what you do and where you are wasting time" (RescueTime b [n.d.]). Here, the individual is addressed as an entrepreneur, who has the same relationship to him- or herself as a manager has to his or her employees. Thus, the entrepreneurial self has a new "urgent need" for control.

However, this kind of self-control is not limited to work, but can be applied to optimising every aspect of life. The optimisation of health seems to be particularly interesting in economic terms. Thus, one self-tracking company claims: "each $1 \%$ reduction in the number of overweight employees saved the company approximately $\$ 1.7$ million annually" (StickK, n.d.). The rationalisation of the production of health obviously also concerns states and health insurance. Several health insurance providers have started to substantially build their bonus programs on self-tracking data, and doctors have started to prescribe self-tracking apps to their patients (Lupton 2015a, IX ff.). The European Commission also assumes that self-tracking technologies contribute to "a more patient-focused healthcare, and supporting the shift towards prevention while at the same time improving the efficiency of the system." (European Commission 2014, 4). Thereby, they expect cost savings of several hundred billion Euro in the health care budget of EU member states.

The "urgent need" that is constituted here presents itself primarily as a need for quantitative data as a basis for an entrepreneurial approach to the self. This problem is also explicitly posed in many self-tracking advertisements. Biotrakr for example advertises with the slogan "you can only manage what you can measure" (2015). This exposes how the need for self-management is systematically connected to the need for data. Thus, we can find empirical traces of an "urgent need" for a new form of control.

To sharpen the identification of the "urgent need", Marx's concepts of exploitation and alienation can serve as a theoretical starting point. In the economic-philosophical manuscripts, Marx describes the connection between exploitation and alienation as follows:

"The more the worker spends himself, the more powerful becomes the alien world of objects which he creates over and against himself, the poorer he himself - his inner world - becomes, the less belongs to him as his own. [...] The worker puts his life into the object; but now his life no longer belongs to him but to the object. [...] The alienation of the worker in his product means not only that his labor becomes an object, an external existence, but that it exists outside him, independently, as something alien to him, and that it becomes a power on its own confronting him. It means that the life which he has conferred on the object confronts him as something hostile and alien." $(1959,22)$

This relationship between exploitation and alienation, or rather of production and control, has a particularly trenchant manifestation in self-tracking. If the "object" or the 
product of work consists of intimate expressions of life, as is often the case with creative or emotional work, the alienation from life takes on a new quality. The work itself requires a cybernetic form of control, such as in self-tracking. This control itself then becomes a sort of work in the Marxian sense, when it produces goods in the form of data. These then become the basis of a second-order control in the moment they are used in advertising or in health educational interventions to manipulate the behaviour of actors. The more the self-tracker "puts his life into the object" when producing data, the more information he or she creates, the more "the life which he has conferred on the object confronts him as something hostile and alien." (Ibid.).

In self-tracking, self-control and classical surveillance seem to merge: in the 'front end', i.e. the interface of an application or website visible to users, information is presented. In the back end, digital activities of users are recorded and a variety of data are collected, such as location or the technical features of the device. These are then turned into commodities in the form of aggregated data packages or personalised profiles. Self-tracking data thus appears in a double form: first, the data that is visible to the users and presented according to their wishes, and second, in the form of a commodity, with different content serving a completely different purpose. In terms of the data commodity, it is not just information on how efficiently the user of RescueTime works which is sold, but information on the topics that the user clicks on or the products the user buys. In digital self-evaluation, these general characteristics of the Internet economy go along with other important qualities that make collected self-measurement data especially valuable. On the one hand, the data is the outcome of comprehensive self-surveillance and thus its significance is much higher than the usual user-tracking or social media profiles. The second feature follows on from the users themselves having an interest in correct data, which leads to them adjusting measurement errors.

This also allows for important conclusions about processes of subjectification which take place in digital self-evaluation. As many studies have shown, with the rise of a post-Fordist economy, the requirements towards workers have changed in a way that can be summarised as the inclusion of the whole subjectivity into the economic process. Capital uses the workforce ever less in the sense of technical competencies. Instead, it demands the integration of the whole person with its manual as well as its cognitive and emotional capabilities (Hirsch 2005, 137). With the term of the entrepreneurial self, Bröckling (2015), following on from Foucault, has shown that in post-Fordism work is often not limited to fixed working hours, but entails for example the optimisation of appearance, health, education or creativity in the sense of human capital. It is important to note that this work on the self is a fundamental part of the production of value in post-Fordism and must be understood as work in the process of the accumulation of capital. Foucault describes how individuals are using certain techniques of the self $^{4}$ to be able to conform to certain social requirements. The embodied self is therefore always created in an altercation with social power structures. The subjectification of work described above is accompanied by new requirements imposed on the workers that could, according to Traue $(2010,273)$, be described as a "post-bureaucratic profile of requirements". Thus, we can theoretically identify a societal "urgent need" for technologies of (self-)control, which foster a Tayloristic rationalisation of work, as well as self-realisation for the entrepreneurial self.

${ }^{4}$ With the term techniques of the self, Michel Foucault (1986) points to forms of self-reference that enable the subjects to transform and rule themselves. He analyses these techniques inter alia with examples of confession and the antique dietetics. 
To answer the question of which way self-tracking reacts to the identified "urgent need" for control, it seems to be useful to turn to the concept of cybernetics. Traue (2010) argues that to be able to fulfil the requirements outlined above, individuals use so called "cybernetic techniques of the self". These allow for a flexible self-optimisation based on feedback loops. Many social media technologies are based on this kind of cybernetic model, in which the subject is understood to be an information processing system that adapts to the norms of its environment as flexibly as possible, even if it is only constantly 'informed' through feedback. In this sense, digital self-evaluation in general and the practices of self-tracking specifically can be understood as cybernetic techniques of the self par excellence (Schaupp 2016c).

Digital evaluation of the self thus reacts to the identified "urgent need" for control in a way that the self-tracking application Beeminder (2017) calls "flexible self-control". To understand the principles of this sort of (self-)control, recourse to cybernetics is helpful. A central problem of this universal science of "communication and control" (Wiener 1948) was the enabling of an automatic self-regulation of complex systems. For this purpose, the cyberneticians conceptualised the homeostat, an abstract machine that is the central model of the cybernetic theory of self-regulation. The homeostat consists of a sensor, a data processing module, and an output module. It was applied to several kinds of problems from the automatic regulation of temperature up to the complete automation of factories (including the management) (see, for example, Beer 1959). The technologies of self-evaluation can thus be understood as a homeostat for subjects imagined as complex systems. They rely entirely on supporting the self-optimisation of the corresponding system by providing relevant feedback, based on self-surveillance.

Jürgen Link $(2006,54)$ also describes the apparatuses of normalisation of modern society as homeostats. However, on the social level he associates the homeostat exclusively with "proto-normalism", which he contrasts with "flexibility-normalism" which is characteristic for the post-Fordist economy. In the latter, "the homeostatic model at large is principally seen as only a subordinate, technical instrument, to keep the dominant dynamic from cracking up, exploding or collapsing." (Ibid., 55). This association of cybernetics with halt, contrasted with dynamism as its opposite, is, however, inaccurate. Dynamism is a cornerstone of cybernetics, and in particular, management cyberneticians such as Stafford Beer stress that cybernetic regulation in a capitalist economy cannot be anything else than the promotion of constant growth: "the ultimately stable state to which a viable system may run (that state where its entropy is unity) is finally rigid and we call that death. If the system is to remain viable, if it is not to die, then we need the extra concept of an equilibrium that is not fixed, but on the move" (Beer 2002/1973, 5). These drastic words that equate halt to death make clear how homeostasis cannot be thought of as a state of static equilibrium, but as a continuous adaption of the system to dynamic conditions in the environment. Growth itself is thus the equilibrium that is aimed for.

In this sense, the answer that self-tracking presents to the "urgent need" for control outlined above is, in cybernetic terms, a homeostatic feedback module for any problem of optimisation in complex systems. It adheres closely to the central principles of cybernetics, which are self-measurement, feedback and self-optimisation. However, selftracking is not about reaching a certain level constituted as normal in order to dispense pressure, as in Link's concept of normalism $(2006,453)$. Instead, its model of homeostasis is about complying with a certain framework of tolerance on a journey to a principally interminable self-optimisation (Bröckling 2006). 


\section{The Macro Apparatus: A Cybernetic Regime?}

Materialist apparatus analysis focuses particularly on detecting politico-economic power relations, which are expressed in the micro apparatuses examined. The approach, outlined in the three steps above (micro apparatus, "urgent need", macro apparatus), is meant to ensure that power relations are identified systematically, instead of framing the research with these assumptions right from the start, especially as this bias is something the Foucauldian apparatus analysis can be accused of. This analysis needs to include the following questions: which ways of acting does the apparatus enable or restrict, materially as well as discursively? Which forms of subjectification are demanded by the interpellations of the apparatus? And which superordinate social structures are stabilised or transformed?

Contrary to the situational style of research suggested for apparatus analysis by Lepa et al. (2014), here, the chosen access is a materialist one. Situational analysis partially follows Latour in making us believe that power effects result spontaneously from immediate "networks of associations" (Latour 1986) of human and non-human actors. However, this is not true for apparatuses as I understand them. In their material condition and institutional context, apparatuses always reach beyond immediate "situations" - they belong to the realm of structures. This is especially problematic when analysing politico-economic power relations. In our case, for example, digital self-evaluation is related to the contemporary dynamics of capitalism. However, the two are not just a flat network of association: capitalism preceded digital self-evaluation. Without claiming that capitalism is the causal reason for self-tracking, it can be said that causality is in no way symmetrical here because capitalism and digital self-evaluation are on different ontological levels. The Latourian flat ontology cannot grasp this problem and is therefore incapable of recognising politico-economic power relations. This is also illustrated by Latour's theoretical development of first denying the relevance of power (1986), then that of capitalism $(1988,173)$ and finally equalling social critique in general to conspiracy theory (2004). As materialist apparatus analysis is specifically about politico-economic power relations, it needs to turn to another meta-theory.

Therefore, I suggest staying with the analytic divide between materiality and discourse as well as structure and action. On this basis, I suggest a methodology that fulfils its critical claim specifically by focusing on power structures, which by definition go beyond singular situations. In this sense, Flatschart $(2015,10)$ outlines a criticalrealist discourse analysis that takes into account the "historical totality" which he calls the "capitalistic-patriarchal society". I follow his approach, but prefer the term macro apparatus or regime as the superordinate structure. The term "capitalist totality" entails two problems. On the one hand, it ignores the theoretical possibility and empirical reality of social relations in which capitalism is not the (central) structuring principle. On the other hand, it runs into danger by falling for an economic determinism in which the possibility for resistance and the substantial openness of social structures is ignored. Instead, the term macro apparatus names a social formation that clearly stands out over singular situations, but does not make a claim for universality. A macro apparatus can rightfully be called so if, in a certain historical situation, a variety of micro apparatuses can be shown that do follow its logic and take part in its reproduction. This does not exclude the simultaneous existence of other macro apparatuses. The macro apparatus illustrated here can be called a cybernetic regime. In the following paragraph, I will elaborate on this term in respect of digital self-evaluation.

As stated above, digital self-evaluation follows the principles of feedback-based cybernetic control. Several other studies have located the revitalisation of these principles of control in other areas as well. Elsewhere, I have pointed to the revitalisation of 
these principles in, for example, police work (Schaupp 2016a, $103 \mathrm{ff}$ ). Raffetseder et al. (2017) elaborate on the comprehensive cybernetisation of organisational control that goes along with the trend of digitization. Traue (2010) shows that cybernetic control does not depend on digital technologies, but is also manifested in psycho-technologies such as systemic consultation. Power's (1997) diagnosis of the omnipresence of different mechanisms of evaluation in the "audit society" can be interpreted as an early form of the macro apparatus of cybernetisation described above. Currently, the discourse around the industrial Internet of Things (loT) shows that the revitalisation of cybernetic control mechanisms is by no means limited to digital self-evaluation, but incorporates a broader politico-economic development. The central demands of the loT discourse clearly follow a cybernetic logic. First, mechanisms for data collection and processing need to be established in order to optimise all the activities within the organisation permanently via immediate feedback. Second, the companies framed as systems will adapt more flexibly to changing conditions in the environment and selectively open up to surroundings. Third, the model of production shifts from mass production planned in the long-term to a black-boxed model of immediate coupling of production and consumption, aiming at the industrial production of batch size $1^{5}$ (Raffetseder 2017). Digital self-evaluation can thus be subsumed under the broader phenomenon of cybernetisation.

Feedback-based control via digital technologies is entangled with the accumulation of capital on different levels. Marx $(1977,231)$ mainly describes the accumulation of capital as the appropriation of labour by capital. This still applies to capital accumulation in post-Fordism. However, the appropriation and commodification of information adds another level to this process. If, for example, work is controlled via self-tracking, the collected data becomes the property of the corresponding company. Thus, the appropriation of work is doubled. Apart from control of the labour itself, control also becomes an immediate part of capital accumulation, not only through the rationalisation of production, but in the sense that control itself creates commodities in the form of information. Data collection and processing are melting into the same process with the production of goods and with control over the production process. Most of the time it is even enabled by the same technical infrastructure. This merger does not only appear in self-tracking but rather is a characteristic of the high-tech capitalism of the early $21 \mathrm{st}$ century. It manifests itself within a cybernetic regime of production and control.

Digital technologies play an important role in this macro apparatus. However, it must be understood as a heterogeneous ensemble of technological, cultural and economic shifts, for which I suggest the term cybernetic regime. The central characteristic of this regime is the merging of information processing, production of goods, and control, under which digital self-evaluation can be subsumed as well. However, there is still the need for more empirical research into the possibility of deviant uses of cybernetic infrastructure, in order not to overlook transformative potentials. Generally, materialist apparatus analysis should not be misunderstood as a functionalist argument for the determination of the micro-level by macro-structures. One must be careful therefore, not to simply replace empirical research with theoretical reflection.

\section{Conclusion: Evaluation of the Evaluation of Self-Evaluation}

The sketch worked out in this paper presents the essential features of a critical analytic frame for digital self-evaluation. In the focus of the proposal lies the question of which power structures are expressed in the examined technologies. Therefore, contrary to

\footnotetext{
${ }^{5}$ Hence, single made products. This tendency is also called mass customization.
} 
the paradigm of flat ontology and the deconstruction of levels currently dominating science and technology studies, it is necessary to distinguish analytically discourse from materiality, and action from structure. A dialectical materialist understanding of the term apparatus allows us to recognise the discursive and material aspects of the apparatus as mutually constituting. It also allows us to combine the analysis of concrete technological constellations with a critical-theoretical reflection. This ensures that power structures hidden from immediate empirical access are neither overlooked nor implied in the basic assumptions but identified analytically.

One question must remain at the centre of a materialist apparatus analysis. How is it possible to take seriously the discursive as well as the materialistic aspects of digital technologies? The material cannot thereby be reduced to the discursive level or vice versa. The central aim is to look at the materiality of digital technologies in a way that puts social power relations into focus.

Following Deleuze, I undertook a separation of micro and macro apparatus. This allows me to put self-evaluation into a politico-economic context. The methodological aim is to build a bridge between the empirical analysis and the socio-theoretical reflection of the analysed technologies. The Foucauldian term "urgent need" functions as a connection between the two levels of analysis, namely micro and macro apparatus, as different micro apparatuses react to it. In this sense, self-tracking can be interpreted as a form of rationalisation of the work on the self, rather than a narcissistic obsession: Each missed run, each excess calorie, each minute dreamt away at work will be measured and logged. The runner, eater, or dreamer will be reminded of it, not to forget to make the very best of him- or herself. However, achievements will not be overlooked anymore either. Each high performance brings an advancement in the ranking of selftracking websites. This perspective enables connections to a concept of the subject in which not only workers and capitalists, but also suspect and police officer are melting into one person.

Digital self-evaluation can also be identified as an expression of a macro apparatus of cybernetisation. However, pointing to the omnipresence of evaluation (Power 1997) is not a sufficient explanation for this phenomenon. Instead, its causes can be found, among others, in the reconciliation of the opposite neoliberal demands for flexibility and rationalisation. This primarily happens in the merging of information processing, production of goods and control. To stress these politico-economic factors, the macro apparatus can tentatively be called a cybernetic regime. This consists in establishing self-optimising systems which manipulate actors to behave efficiently. As it is characterised by a multiplicity of apparatuses of control with subjectifying effects, which in turn remain uncontrolled by the subjects themselves, a state of alienation can be assumed under the cybernetic regime. However, in the context of apparatus analysis, alienation does not mean a deviation from a non-alienated original condition as Marx's anthropological conception of the subject might indicate (cf. Flügel-Martinsen 2010). Instead, when asking about the subjectifying effects of the apparatus, the subject must always be understood as having been produced already. Someone is alienated, then, as Jaeggi $(2014,219)$ explains, "if she cannot react to her own given conditions". In our context, the term alienation also seems to be useful for showing how the identified macro apparatus reflects on the subjects.

Thus, the cybernetic regime is manifested in a variety of micro apparatuses of feedback that ask for a total evaluation. Our expressions of life have to be evaluated digitally. This evaluation must be evaluated by the social sciences. Finally, the evaluation of the evaluation must be evaluated critically. The lucky ones can sell their evaluations. 
Whoever does not choose to evaluate has to become the "idiot" (Dany 2014), fooling all feedback loops.

\section{References}

Agamben, Giorgio. 2009. What is an Apparatus? And Other Essays. Stanford: Stanford University.

Barad, Karen. 2007. Meeting the Universe Halfway: Quantum Physics and the Entanglement of Matter and Meaning. Durham, NC: Duke University Press.

Beeminder. 2017. Overview. Accessed July 26, 2017. https://www.beeminder.com/overview

Beeminder. 2015. Home. Accessed May 4, 2015. https://www.beeminder.com/

Beer, Stafford. 2002/1973. Fanfare for Effective Freedom. Cybernetic Praxis in Government. St. Gallen: Cwarel Isaf Institute.

Beer, Stafford. 1959. Cybernetics and Management. London: English Universities Press.

Biotrakr. 2015. Home. Accessed September 8, 2015. http://biotrakr.de/

Bröckling, Ulrich. 2015. The Entrepreneurial Self. London: Sage.

Bröckling, Ulrich. 2006. Und ... Wie War Ich? Über Feedback. Mittelweg 36 (15): 27-44.

Dany, Hans-Christian. 2014. Morgen werde ich Idiot. Kybernetik und Kontrollgesellschaft. Hamburg: Nautilus.

Deleuze, Gilles. 1997. Desire and Pleasure. In Foucault and his Interlocutors, edited by Arnold I. Davidson, 183-192. Chicago: University of Chicago.

Duttweiler, Stefanie, Robert Gugutzer, Jan-Hendrik Passoth and Jörg Strübing, eds. 2016. Leben nach Zahlen. Self-Tracking als Optimierungsprojekt? Bielefeld: Transcript.

Eugster, David. 2013. Mikrodispositive: Die kurze Geschichte eines Automatenladens. In Verortungen des Dispositiv-Begriffs. Theorie und Praxis der Diskursforschung, edited by Caborn Wengler, Joannah. Wiesbaden: VS.

European Commission. 2014. Green Paper on Mobile Health. Brussels: European Commission.

Fairclough, Norman. 2013. Critical Discourse Analysis: The Critical Study of Language. London: Routledge.

Fairclough, Norman. 2005. Peripheral Vision. Discourse Analysis in Organization Studies: The Case for Critical Realism. Organization Studies 26 (6): 915-939.

Fairclough, Norman, Bob Jessop and Andrew Sayer. 2004. Critical Realism and Semiosis. In Realism Discourse and Deconstruction, edited by Jonathan Joseph and John M. Roberts, 23-43. London: Routledge.

Fielding, Nigel G., Raymond M. Lee and Grant Blank, eds. 2008. The Sage Handbook of Online Research Methods. London: Sage.

Flatschart, Elmar. 2015. Critical Realist Critical Discourse Analysis: A Necessary Alternative to Post-Marxist Discourse Theory. Journal of Critical Realism 15 (1): 1-32.

Flügel-Martinsen, Oliver. 2010. Entfremdung und Subjektivität bei Marx. Zwei konkurrierende Denkwege? In Marx-Engels-Jahrbuch 2009, edited by Gerald Hubman and Claudia Reichel, 81-99. Berlin: Akademie.

Foucault, Michel. 1985. The History of Sexuality, Vol. II: The Use of Pleasure. New York: Random House.

Foucault, Michel. 1980. Power/Knowledge. Selected Interviews and Other Writings $1972-$ 1977. New York: Pantheon.

Fuchs, Christian. 2009. Information and Communication Technologies and Society. A Contribution to the Critique of the Political Economy of the Internet. European Journal of Communication, 24 (1): 70-87.

Goffey, Andrew. 2008. Algorithm. In: Software Studies. A Lexicon, edited by Matthew Fuller. Cambridge: MIT.

Hirsch, Joachim. 2005. Materialistische Staatstheorie. Transformationsprozesse des kapitalistischen Staatensystems. Hamburg: VSA. 
Jaeggi, Rahel. 2014. Alienation. New York: Columbia University Press.

Latour, Bruno. 2004. Why Has Critique Run out of Steam? From Matters of Fact to Matters of Concern, Critical Inquiry 30 (2): 225-248.

Latour, Bruno. 1988. The Pasteurization of France. Cambridge, MA: Harvard University Press.

Latour, Bruno. 1986. The Powers of Association. In: Power, Action, Belief, edited by John Law, 264-280. London: Routledge.

Leonardi, Paul M. 2013. Theoretical Foundations for the Study of Sociomateriality. Information and Organization 23: 59-76.

Lepa, Steffen, Friedrich Krotz and Anne-Kathrin Hoklas. 2014. Vom ,Medium' zum ,Mediendispositiv'. Metatheoretische Überlegungen zur Integration von Situations- und Diskursperspektive bei der empirischen Analyse mediatisierter sozialer Welten. In Die Mediatisierung sozialer Welten. Synergien empirischer Forschung, edited by Friedrich Krotz, Cathrin Despotović and Merle-Marie Kruse, 115-141. Wiesbaden: Springer.

Link, Jürgen. 2006. Versuch über den Normalismus. Wie Normalität produziert wird. Göttingen: Vandenhoeck \& Ruprecht.

Ludes, Peter. 2001. Schlüsselbild-Gewohnheiten. Visuelle Habitualisierungen und Visuelle Koordination. In: Kommunikation Visuell. Das Bild als Forschungsgegenstand Grundlagen und Perspektiven, edited by Thomas Knieper and Marion Müller, 64-78. Köln: Halem.

Lupton, Deborah, ed. 2015a. Beyond Techno-Utopia: Critical Approaches to Digital Health Technologies. Basel: MDPI.

Lupton, Deborah. 2015b. Quantified Sex: A Critical Analysis of Sexual and Reproductive Self-Tracking Using Apps. Culture, Health \& Sexuality, 17 (4): 440-453.

Marx, Karl. 1977. Das Kapital. MEW Band 23. Berlin: Dietz.

Marx, Karl. 1959. Economic and Philosophic Manuscripts of 1844. Moscow: Progress.

Marx, Karl and Friedrich Engels. 1971. Werke. Band 13. Berlin: Dietz.

Power, Michael. 1997. The Audit Society: Rituals of Verification. Oxford: Oxford University.

Quantified Self. n.d. Home. Accessed July 26, 2017. http://quantifiedself.com/

Raffetseder, Eva-Maria, Simon Schaupp and Philipp Staab. 2017: Kybernetik und Kontrolle. Algorithmische Arbeitssteuerung und betriebliche Herrschaft. PROKLA 187: 227-247.

RescueTime. a (n.d.). FAQ. Accessed July 26, 2017. https://www.rescuetime.com/faq

ResqueTime. b (n.d.). Plans. Acessed September 10, 2015. www.rescuetime.com/plans

Runtastic. a (n.d.). Dieter Baumann. Accessed July 26, 2017. https://www.runtastic.com/shop/en/baumann

Runtastic. b (n.d.). Günther Weidlinger. Accessed July 26, 2017. https://www.runtastic.com/shop/en/weidlinger

Sayer, Andrew. 2000. Realism and Social Science. London: Sage.

Schaupp, Simon. 2016a. Digitale Selbstüberwachung. Self-Tracking im kybernetischen Kapitalismus. Heidelberg: Graswurzelrevolution.

Schaupp, Simon. 2016b. Measuring the Entrepreneur of Himself. Gendered Quantification in the Self-Tracking Discourse. In Lifelogging. Digital Self-Tracking and Lifelogging: Between Disruptive Technology and Cultural Transformation, edited by Stefan Selke, 249-266. Wiesbaden: Springer.

Schaupp, Simon. 2016c. „Wir nennen es flexible Selbstkontrolle“. Self-Tracking als Selbsttechnologie des kybernetischen Kapitalismus. In Leben nach Zahlen. Self-Tracking als Optimierungsprojekt?, edited by Duttweiler, Stefanie, Robert Gugutzer, Jan-Hendrik Passoth and Jörg Strübing, 63-86. Bielefeld: Transcript.

StickK. n.d. Corporate. Accessed July 26, 2017. http://www.stickk.com/corporate

Traue, Boris. 2010. Das Subjekt der Beratung. Zur Soziologie einer Psycho-Technik. Bielefeld: Transcript.

Vannini, Phillip, ed. 2009. Material Culture and Technology in Everyday Life: Ethnographic Approaches. New York: Peter Lang. 
Volkoff, Olga and Diane M. Strong. 2013. Critical Realism and Affordances. Theorizing ITassociated organizational change processes. MIS Quarterly, 37 (3): 819-834.

Weintraub, Karen. 2013. Quantified Self: The Tech-Based Route to a Better Life? BBC Future, 3 January. Accessed July 26, 2017. http://www.bbc.com/future/story/20130102-selftrack-route-to-a-better-life

Whitson, Jennifer R. 2013. Gaming the Quantified Self. Surveillance \& Society 11: 163-176.

Wiener, Norbert. 1948. Cybernetics, or Control and Communication in the Animal and the Machine. Cambridge: MIT Press.

Wodak, Ruth and Michael Meyer, eds. 2009. Methods for Critical Discourse Analysis. London: Sage.

\section{About the Author}

Simon Schaupp

Simon Schaupp is research associate at the Post/Doc Lab Reorganizing Industries at the Munich Center for Technology in Society of the Technical University of Munich. His research focus is the sociology of media and technology, industrial sociology and critical theory. 